\title{
Multi-scale immunoepidemiological modeling of within-host and between-host HIV dynamics: Systematic review of mathematical models
}

\author{
Nargesalsadat Dorratoltaj $^{1}{ }^{\text {， Ryan Nikin-Beers }}{ }^{2}$, Stanca M Ciupe $^{2}{ }^{\text {, }}$ Stephen G Eubank ${ }^{3}$, Kaja M Abbas ${ }^{\text {Corresp. }}{ }^{1}$ \\ 1 Department of Population Health Sciences, Virginia Tech, Blacksburg, United States \\ 2 Department of Mathematics, Virginia Tech, Blacksburg, United States \\ 3 Biocomplexity Institute, Virginia Tech, Blacksburg, United States \\ Corresponding Author: Kaja M Abbas \\ Email address: kaja.abbas@vt.edu
}

Objective: The objective of this study is to conduct a systematic review of multi-scale HIV immunoepidemiological models to improve our understanding of the synergistic impact between the HIV viral-immune dynamics at the individual level and HIV transmission dynamics at the population level.

Background: While within-host and between-host models of HIV dynamics have been well studied at a single scale, connecting the immunological and epidemiological scales through multi-scale models is an emerging method to infer the synergistic dynamics of HIV at the individual and population levels.

Methods: We reviewed 9 articles using the PRISMA (Preferred Reporting Items for Systematic Reviews and Meta-Analyses) framework that focused on the synergistic dynamics of HIV immunoepidemiological models at the individual and population levels.

Results: HIV immunoepidemiological models simulate viral immune dynamics at the within-host scale and the epidemiological transmission dynamics at the between-host scale. They account for longitudinal changes in the immune viral dynamics of HIV+ individuals, and their corresponding impact on the transmission dynamics in the population. They are useful to analyze the dynamics of HIV super-infection, co-infection, drug resistance, evolution, and treatment in HIV+ individuals, and their impact on the epidemic pathways in the population. We illustrate the coupling mechanisms of the within-host and between-host scales, their mathematical implementation, and the clinical and public health problems that are appropriate for analysis using HIV immunoepidemiological models.

Conclusion: HIV immunoepidemiological models connect the within-host immune dynamics at the individual level and the epidemiological transmission dynamics at the population level. While multi-scale models add complexity over a single-scale model, they account for the time varying immune viral response of HIV+ individuals, and the corresponding impact on the time-varying risk of transmission of HIV+ individuals to other susceptibles in the population. 


\title{
Multi-scale Immunoepidemiological Modeling of Within-host and Between-host HIV Dynamics: Systematic Review of Mathematical Models
}

\author{
Nargesalsadat Dorratoltaj, ${ }^{1^{*}}$ Ryan Nikin-Beers, ${ }^{2^{*}}$ \\ Stanca M. Ciupe, ${ }^{2}$ Stephen G. Eubank, ${ }^{3}$ Kaja M. Abbas ${ }^{1}$ \\ 1 Department of Population Health Sciences, Virginia Tech \\ 2 Department of Mathematics, Virginia Tech \\ ${ }^{3}$ Biocomplexity Institute, Virginia Tech
}

*These authors contributed equally to this work.

August 31, 2017

\begin{abstract}
Objective: The objective of this study is to conduct a systematic review of multi-scale HIV immunoepidemiological models to improve our understanding of the synergistic impact between the HIV viral-immune dynamics at the individual level and HIV transmission dynamics at the population level.

Background: While within-host and between-host models of HIV dynamics have been well studied at a single scale, connecting the immunological and epidemiological scales through multi-scale models is an emerging method to infer the synergistic dynamics of HIV at the individual and population levels.

Methods: We reviewed 9 articles using the PRISMA (Preferred Reporting Items for Systematic Reviews and Meta-Analyses) framework that focused on the synergistic dynamics of HIV immunoepidemiological models at the individual and population levels.

Results: HIV immunoepidemiological models simulate viral immune dynamics at the within-host scale and the epidemiological transmission dynamics at the between-host scale.
\end{abstract}


They account for longitudinal changes in the immune viral dynamics of HIV+ individuals, and their corresponding impact on the transmission dynamics in the population. They are useful to analyze the dynamics of HIV super-infection, co-infection, drug resistance, evolution, and treatment in HIV+ individuals, and their impact on the epidemic pathways in the population. We illustrate the coupling mechanisms of the within-host and between-host scales, their mathematical implementation, and the clinical and public health problems that are appropriate for analysis using HIV immunoepidemiological models.

Conclusion: HIV immunoepidemiological models connect the within-host immune dynamics at the individual level and the epidemiological transmission dynamics at the population level. While multi-scale models add complexity over a single-scale model, they account for the time varying immune viral response of HIV+ individuals, and the corresponding impact on the time-varying risk of transmission of HIV+ individuals to other susceptibles in the population. 


\section{INTRODUCTION}

HIV prevalence and mortality were 38.8 million and 1.2 million deaths respectively in 2015 , with annual incidence being relatively constant at 2.6 million per year from 2005 to 2015 (Wang et al. (2016)). Access to big data and emergence of unanswered questions enable novel methods of mathematical models to connect within-host immune viral dynamics at the individual level, and the between-host epidemiological transmission of infectious diseases at the population level (Gog et al. (2015)). Mathematical models of HIV dynamics have been extensively studied using single-scale based models at the immunological and epidemiological scales (Perelson \& Ribeiro (2013); Akpa \& Oyejola (2010)). The immunological models focus on the within-host immune viral dynamics at the individual level, while the epidemiological models focus on the between-host transmission dynamics at the population level. Multi-scale immunoepidemiological modeling is an emerging method to study the synergistic dynamics of HIV at the individual and population levels (DebRoy \& Martcheva (2008); Yeghiazarian et al. (2013); Handel \& Rohani (2015)).

\section{Epidemiological models}

Epidemiological modeling of HIV infection started in 1985 (Curran et al. (1985)). Epidemiological models of HIV infections assign each individual to one of the following states: susceptible or infected. Infected individuals may transmit HIV to susceptible hosts with the same transmission rate over the course of disease, and experience specific duration of infection (Isham (1988); Hyman \& Ann Stanley (1988); Haberman (1990)). However, time since infection, other co-infections, and a host's biological factors such as age, sex, genetic susceptibility, and immune status cause variation in infectiousness of HIV+ individuals (Cassels et al. (2008)). Host heterogeneity among different ages, gender and risk groups is significant due to the multiple routes of transmission - sexual transmission, intravenous transmission through needle sharing, blood transfusion, and mother-to-child vertical transmission. 


\section{Immunological models}

Within-host models of HIV at the individual level study the dynamics of HIV and target immune cells - CD4+ T cells, macrophages, and dendritic cells. The complexity of the models vary from molecular level (Reddy \& Yin (1999); Zarrabi et al. (2010); Hosseini \& Mac Gabhann (2012)), cellular level (Anderson \& May (1992); McLean (1993); Ho et al. (1995); Perelson et al. (1996); Kirschner (1996); De Boer \& Perelson (1998); Banks et al. (2008); Hosseini \& Mac Gabhann (2012); Perelson \& Ribeiro (2013)), and tissue level (Spouge et al. (1996)). The within-host immunological models analyze the mechanisms of HIV pathogenesis and prognosis from acute, latent and late stages of HIV infection to AIDS phase.

\section{Immunoepidemiological models}

Figure 1 illustrates that the transmission dynamics of HIV in the population is dependent on the immune viral dynamics of HIV+ individuals. Immunoepidemiological models factor the HIV transmission dynamics at the population level as a function of within-host immune viral responses at the individual level (DebRoy \& Martcheva (2008); Yeghiazarian et al. (2013); Hellriegel (2001)).

\section{Clinical and public health significance}

HIV immunoepidemiological models focus on solutions for the following questions of clinical and public health significance (Feng et al. (2011)):

- How does within-host immune-viral dynamics of HIV affect incidence at the population level?

- How does population level transmission dynamics of HIV affect viral evolution at the individual level?

In this study, we review the multi-scale modeling methods that connect the within-host and between-host scales of HIV models. Understanding the relation between these two scales is key to understand HIV prognosis, transmission risk, and intervention effectiveness (Pepin et al. (2010)). 


\section{METHODS}

\section{Search strategy}

We searched the PubMed database for articles published from December 1, 1985 to June 1, 2017 with the terms: (HIV and ("multi-scale" or "immunoepidemiology" or "nested model" or ("withinhost" and "between host") or ("within-host" and "among host") or ("within-host" and ("epidemiology" or "epidemiological")))).

\section{Data abstraction and synthesis}

The data abstraction and synthesis process was conducted by two authors (ND and RNB) independently, and includes the following four steps: identification, screening, eligibility, and inclusion. We resolved discordant decisions through consensus. During the identification step, articles were identified using the above search strategy. During the screening step, duplicate articles were removed, and titles and abstract of the remaining articles were screened to determine their relevance to our study. During the eligibility step, full texts of the articles were analyzed to determine their relevance to our study.

\section{Inclusion and exclusion criteria}

The inclusion criteria were articles focused on multi-scale immunoepidemiological modeling of HIV dynamics. The exclusion criteria were articles that focused on genetic epidemiology, molecular epidemiology, parasitology, ecology, evolutionary study, and experimental studies.

\section{PRISMA process}

Figure 2 illustrates the process flow diagram of identification, screening, eligibility, and inclusion of articles for the systematic review, using the PRISMA (Preferred Reporting Items for Systematic Reviews and Meta-Analyses) framework (Moher et al. (2009)). 89 articles were uniquely 
identified, 66 articles were screened out, and 9 articles were found eligible to be included in this systematic review. This systematic review includes a qualitative synthesis and does not include the quantitative synthesis of a meta-analysis (not applicable for this study). 


\section{RESULTS}

Table 1 illustrates the characteristics of HIV immunoepidemiological modeling studies included in this systematic review. The objective, model implementation, immunoepidemiological link between within-host and between-host models, and significant inferences of these studies are summarized in the table.

\section{Within-Host Scale of HIV Immunoepidemiological Models}

The within-host scale of HIV immunoepidemiological models simulate the immune-viral dynamics of HIV, which can later be used to determine the impact on transmission between hosts. We categorize the within-host models by whether they model a single strain of HIV, super-infection, drug resistance, evolution, co-infection and therapeutic interfering particles. The immunological scale includes the primary state variables of uninfected CD4+ T cells concentration $(T)$, infected CD4+ T cells concentration $\left(T^{*}\right)$ and viral load $(V)$, and the corresponding parameters for the immune-viral dynamics between these state variables (Anderson \& May (1992); Perelson et al. (1996); De Boer \& Perelson (1998)).

\section{HIV infection with single strain}

In this approach, it is assumed that there is only one strain of HIV that infects the target cells. No additional features such as mutation, super-infection, or co-infection are considered at the withinhost scale. We found three models that include only one strain of HIV at the within-host scale (Shen et al. (2015); Sun et al. (2016); Yeghiazarian et al. (2013)). An example of the basic dynamics are shown in Table 2, which also assumes that viral shedding rate $(s)$ has negative effect on the viral load (V) within-host (DebRoy \& Martcheva (2008)). This model can be modified to include the effects of drug therapy, which affect the viral production rate and the viral infectivity rate (Shen et al. (2015); Sun et al. (2016); Yeghiazarian et al. (2013)). 


\section{HIV super-infection}

HIV super-infection occurs when individuals infected with a single HIV strain are infected with a second HIV strain. and Li included HIV infection with multiple strains in their model, with the assumption of complete competitive exclusion between the strains at the within-host scale. In this context, the strain with the larger reproduction rate becomes dominant. They studied the impact of virulence of different strains on the equilibrium at the individual and population scales (Martcheva \& Li (2013)). Table 3 shows the schematic and formulation of this model.

\section{HIV drug resistance}

Drug resistance can be acquired through mutations of drug-sensitive strains within-host or through direct transmission of drug-resistant strains. Saenz and Bonhoeffer included HIV infection with drug resistant strains in their model, and studied the effects of antiretroviral treatment (ART) on both drug-sensitive and drug-resistant strains (Saenz \& Bonhoeffer (2013)). Table 4 shows the schematic and formulation of this model.

\section{HIV evolution}

Studies have modeled HIV viral evolution within-host and its impact on transmission between hosts (Lythgoe et al. (2013); Doekes et al. (2017)). They investigate the trade-off between increased virus replication and virulence and decrease in virus transmission. Doekes et al also included longlived reservoirs of latently infected CD4+ T cells to determine their impact on HIV within-host competition (Doekes et al. (2017)).

\section{HIV co-infection}

HIV co-infection with sexually transmitted infections among high risk groups (Abu-Raddad et al. (2008)), and/or co-infection with endemic infections such as malaria (Cuadros et al. (2011)) have direct impact on increasing the transmission rate of both infections. Cuadros and García-Ramos 
incorporated HIV co-infection dynamics in the within-host immune model (Callaway \& Perelson (2002); Stafford et al. (2000); Nowak \& May (2000)) to address increased immune response and increased risk of transmission, and evaluated their impact on HIV epidemics (Cuadros \& GarcíaRamos (2012)). Table 5 shows the schematic and formulation of this model.

\section{HIV and therapeutic interfering particles}

Therapeutic interfering particles (TIPs) are an emerging drug therapy where therapeutic versions of the pathogen are manufactured to attack viral replication processes and can be transmitted between hosts (Metzger et al. (2011)). In the within-host model developed by Metzger et al, HIV and TIPs are treated as separate viral strains. The model includes CD4+ T cells infected with HIV only, CD4+ T cells infected with TIPs only, and CD4+ T cells dually infected with HIV and TIPs (Metzger et al. (2011)).

\section{Between-Host Scale of HIV Immunoepidemiological Models}

Between-host scales of HIV immunoepidemiological models are based on the susceptible-infectious ( $S I$ ) epidemic model, which have been used extensively to study HIV transmission dynamics in a homogeneous population and random mixing of susceptibles $(S)$ and HIV+ individuals $(I)$ (Isham (1988)). Table 6 shows the schematic and formulation of the $S I$ epidemic model. Studies have extended the homogeneous population structure of the $S$ I model to incorporate different populations of infected individuals. We categorize the studies by how they divide the infected population, and thus how the transmission rates between these classes differ. We find heterogeneity in HIV transmission rates depending on the stages of HIV infection (Cuadros \& García-Ramos (2012); Yeghiazarian et al. (2013); Sun et al. (2016); Shen et al. (2015)), and the dynamics of super-infection (Martcheva \& Li (2013)), drug resistance (Saenz \& Bonhoeffer (2013)), evolution (Lythgoe et al. (2013); Doekes et al. (2017)), and therapeutic interfering particles (Metzger et al. (2011)). 


\section{Acute, latent and late stages of HIV infection}

Previous studies have shown that transmission rates differ depending on whether the infected population is in the acute, latent, or AIDS stages (Hollingsworth et al. (2008)). This conclusion can be incorporated into immunoepidemiological models by categorizing the infected population into different stages (Cuadros \& García-Ramos (2012); Yeghiazarian et al. (2013); Sun et al. (2016); Shen et al. (2015); Saenz \& Bonhoeffer (2013)). Cuadros and García-Ramos extended the model so that the HIV+ sub-populations also differed by sexual-risk activity (Cuadros \& García-Ramos (2012)). Yeghiazarian et al divided the infected population into stages to evaluate the timing of treatment initiation at the individual level, and its impact on HIV transmission at the population level. They assumed treatment initiation can start during any stage of HIV infection after diagnosis (Yeghiazarian et al. (2013)).

\section{HIV super-infection}

HIV infected individuals are categorized based on the strains of infection. Due to the assumption of competitive exclusion at the within-host level in the model developed by Martcheva and Li, susceptible individuals only become infected with one of the strains. Thus, only infected individuals having the dominant within-host strain can super-infect individuals with the lesser within-host strain (Martcheva \& Li (2013)).

\section{HIV drug resistance}

Drug-resistant strains can emerge during antiretroviral therapy (ART) (Rong et al. (2007)), or can be transmitted between individuals who have never been exposed to ART (Hué et al. (2009)), which may lead to treatment failure if ART is begun (Hamers et al. (2011)). Saenz and Bonhoeffer thus categorize the infected population into those with only drug-sensitive or only drug-resistant strains with or without treatment, and those with drug-sensitive strains that develop drug-resistance while receiving treatment (Saenz \& Bonhoeffer (2013)). Table 7 shows the schematic and formulation of 
this model.

\section{HIV evolution}

Depending on virulence of the strain, infected individuals are categorized by the strain with which they initially became infected (Doekes et al. (2017); Lythgoe et al. (2013)). Because it is assumed that all other strains develop from an initial strain and only the most virulent strain is transmitted, infected individuals can end up infecting others with a different strain than they were initially infected. Table 8 shows the schematic and formulation of this model.

\section{HIV and therapeutic interfering particles}

The infected population is divided into classes of those infected with HIV only, those infected with Therapeutic Interfering Particles (TIPs) only, and those infected dually with HIV and TIPs. The infected population is also divided into these classes during different stages of infection (Metzger et al. (2011)). Table 9 shows the schematic and formulation of this model.

\section{Coupling Within-Host and Between-Host Scales of HIV Immu-} noepidemiological Models

The potential for transmission between HIV+ individuals to susceptibles is affected by the viral load of infected hosts (Attia et al. (2009)). In all the models that we analyzed in this systematic review, the transmission rate between hosts is dependent on the within-host viral load. We categorize the models into those where the transmission rate is a function of viral load and those where the equilibria of the within-host model are used to determine the transmission rate. 


\section{HIV transmission rate as a function of viral load}

The within-host and between-host scales of HIV immunoepidemiological models are coupled by basing the transmission rate on the time-varying viral load since infection. The viral load (and thus the transmission rate) is high during the acute and late stages of HIV infection while being low during the latent stage (Hollingsworth et al. (2008); DebRoy \& Martcheva (2008)). Table 10 shows the formulation of this model. Unlike the basic $S I$ epidemiological model that assumes constant transmission rate $(\beta)$, the between-host model assigns time-varying transmission rate, which is dependent on the non-linear viral immune dynamics of HIV in the within-host model.

In some models, the transmission rate depends on the viral load continuously over time (Shen et al. (2015); Martcheva \& Li (2013); Saenz \& Bonhoeffer (2013)). Saenz and Bonhoeffer also distinguished between drug-resistant and drug-sensitive strains and their corresponding impact on the transmission rate (Saenz \& Bonhoeffer (2013)). Martcheva and Li made the death of infected individuals depend on the viral load over time, since the AIDS stage is associated with high viral load (Martcheva \& Li (2013)).

In the context of HIV evolution, while the transmission rate varies through time depending on the viral load, the viral load is also modeled to distinguish between different strains (Doekes et al. (2017); Lythgoe et al. (2013)). The transmission rate depends on a predefined infectivity profile which changes depending on the stage of infection, and the frequency of the different viral strains in an infected population. Doekes et al made the transmission rate depend on the frequency of viral strains that were only in actively infected CD4+ T cells (Doekes et al. (2017)).

The within-host viral load can be used to individualize the transmission rate over time (Yeghiazarian et al. (2013); Sun et al. (2016)). The CD4+ T cell count can also be used to determine the stage of infection (Yeghiazarian et al. (2013)).

\section{HIV transmission rate using viral load equilibrium}

Another method of linking the within-host and between-host scales is to use the within-host model to determine an equilibrium for the viral load. This equilibrium can then be used as a constant pa- 
rameter in the between-host model, which can then be analyzed further by differing the parameters of the within-host model (Metzger et al. (2011); Cuadros \& García-Ramos (2012)). Cuadros and García-Ramos accounted for the amplified viral load due to co-infection and the corresponding increase in HIV transmission rate (Cuadros \& García-Ramos (2012)). Metzger et al determined the differing viral loads associated with HIV and TIPs, and their effect on the transmission probabilities between infected populations (Metzger et al. (2011)).

\section{Clinical and Public Health Implications}

\section{HIV virulence}

Clinical studies have shown that HIV has evolved an intermediate level of virulence at the withinhost level that optimizes the transmission potential of the virus at the population level (Fraser et al. (2007)). However, at the within-host level, HIV can evolve quickly (Lemey et al. (2006)), virulence increases during the course of the infection (Kouyos et al. (2011)), and infections with higher replicative capacities have higher virulence (Kouyos et al. (2011)). Replicative capacities also increase over the course of infection, albeit slowly (Kouyos et al. (2011)). Because of this behavior of HIV at the within-host level, it might be expected that HIV would evolve a high virulence at the within-host level, even if it did not optimize the transmission potential at the population level. To understand these seemingly contradictory results, immunoepidemiological models were used, which incorporated these behaviors of HIV at the within-host level (Lythgoe et al. (2013); Doekes et al. (2017)). The model developed by Lythgoe et al found that small rates of within-host evolution optimize the transmission potential at the population level, whereas higher rates of within-host evolution lead to high levels of virulence, but lower transmission potential (Lythgoe et al. (2013)). Lythgoe et al suggest that the clinical observations seen in HIV may be a result of a within-host fitness landscape that is complex to traverse, since this leads to smaller rates of within-host evolution (Lythgoe et al. (2013)). They also suggest the effect of the adaptive immune response may play a role in explaining the observed behavior (Lythgoe et al. (2013)). 
Based off the results from Lythgoe et al, a similar model was constructed by Doekes et al, which included a latent reservoir of CD4+ T cells at the within-host level (Doekes et al. (2017)). They found that this latent reservoir may be responsible for delaying the evolutionary dynamics at the within-host level, which then leads to the transmission potential being optimized (Doekes et al. (2017)).

\section{Antiretroviral therapy}

While there is uncertainty over the timing of initiating antiretroviral therapy, some studies have suggested there may be benefits to beginning treatment early (When To Start Consortium et al. (2009); Cohen (2011)). Experimental studies also suggest that because ART reduces transmissibility, increasing coverage levels may reduce the prevalence of HIV (Cohen (2011)). However, drug-resistant strains can emerge, which can lead to treatment failure (Hué et al. (2009); Hamers et al. (2011)). Immunoepidemiological models were used to understand these effects of ART, focusing on treatment timing (Sun et al. (2016); Yeghiazarian et al. (2013)), coverage levels (Shen et al. (2015)), and drug resistance (Saenz \& Bonhoeffer (2013); Sun et al. (2016)). The models showed that in general, initiating treatment early (Yeghiazarian et al. (2013); Sun et al. (2016)), increasing coverage (Shen et al. (2015); Saenz \& Bonhoeffer (2013)), and increasing effectiveness of ART (Shen et al. (2015); Saenz \& Bonhoeffer (2013)) reduces the prevalence of HIV.

However, in certain cases, increases in the prevalence of HIV may occur even with early treatment initiation, increased coverage, and increased effectiveness of ART to drug-sensitive strains. Models showed that as ART coverage levels increase, the prevalence of drug-resistant strains increase, which cause an increase in HIV prevalence (Saenz \& Bonhoeffer (2013)). Prevalence can also increase if drug-resistant strains cause the drug efficacy to decrease significantly (Sun et al. (2016)). These results imply that there may be an optimal therapy coverage level that will minimize the number of infections (Saenz \& Bonhoeffer (2013)). Therefore, in these cases, the models suggest that HIV prevalence can be reduced by focusing efforts on decreasing the risk of drug resistance emergence (Saenz \& Bonhoeffer (2013)). 
Clinical studies have observed that under certain conditions, the prevalence of HIV increases when ART coverage levels increase (Zaidi et al. (2013)). Zaidi et al hypothesize that since ART reduces viral load, patients may live longer, and thus have the ability to infect more people (Zaidi et al. (2013)). Immunoepidemiolgical models also observed this effect (Shen et al. (2015)), including a model of super-infection (Martcheva \& Li (2013)). Both model outcomes are consistent with the hypothesis of Zaidi et al, since the models find that the increased prevalence is due solely to decreases in viral load (Shen et al. (2015); Martcheva \& Li (2013)). The model developed by Shen et al found that this effect can be minimized if drug effectiveness is high (Shen et al. (2015)).

\section{Therapeutic interfering particles}

Clinical trials have shown that therapeutic interfering particles (TIPs) have the potential to reduce within-host viral load (Levine et al. (2006)) and transmit between hosts (Aaskov et al. (2006)). Experimental studies have also shown that HIV transmission rates between hosts depend on the within-host viral load (Fraser et al. (2007)). Based on these assumptions, an immunoepidemiological model is developed, which deploys TIPs to a small proportion (1\%) of the population (Metzger et al. (2011)). The effect on HIV prevalence due to deploying TIPs is compared to deploying ART and to deploying a hypothetical HIV vaccine. When TIPs have the ability to transmit between hosts, the model shows deploying TIPs reduces HIV prevalence to lower levels than deploying ART therapy or deploying vaccines. However, the model shows that if TIPs do not have the ability to transmit between hosts, then there is minimal effect on the reduction of HIV prevalence (Metzger et al. (2011)). While more study of TIPs is needed, TIPs have the potential to be an effective therapy than either ART or vaccines.

\section{HIV co-infection}

Experimental studies suggest that co-infection may be responsible for increases seen in set-point viral load (spVL) at the within-host level over time (Modjarrad \& Vermund (2010)). These increases due to co-infection vary substantially within-host (Kublin et al. (2005)). Also, the concen- 
trations of co-infection in high-risk groups versus low-risk groups may affect how HIV spreads in the general population (Abu-Raddad et al. (2008)). To study the mechanisms responsible for these effects of co-infection, an immunoepidemiological model was developed (Cuadros \& GarcíaRamos (2012)). They found that populations with higher spVL lead to higher increases in viral load due to co-infection, whereas populations with lower spVL leads to lower increases in viral load due to co-infection. This leads to a greater chance of co-infection increasing the prevalence of HIV in populations with high average spVL (Cuadros \& García-Ramos (2012)). Therefore, the effects of co-infection may be mitigated by identifying the viral factors that can reduce the spVL in the population. 


\section{DISCUSSION}

\section{Mathematical implementation of HIV immunoepidemiological models}

We conducted this systematic review of HIV immunoepidemiological models to improve our understanding and analysis of the synergistic dynamics of HIV prognoses at the individual level and the transmission dynamics at the population level. With respect to mathematical implementation, within-host models are implemented using ordinary differential equations which determine the HIV transmission rate for the between-host model. If the within-host model is used at equilibrium to determine constant parameters for the between-host model, ordinary differential equations are used for the between-host model as well (Cuadros \& García-Ramos (2012); Metzger et al. (2011)). Integro-differential equations with delay are used in the between-host scales of HIV immunoepidemiological models to study HIV evolution dynamics (Lythgoe et al. (2013); Doekes et al. (2017)). Partial differential equations are used for the between-host model if the transmission rate changes continuously with the within-host viral load over time (Shen et al. (2015); Martcheva \& Li (2013); Saenz \& Bonhoeffer (2013)). Individual or agent-based based models analyze the HIV transmission dynamics between individual agents in a population, wherein the HIV transmission rates of each individual is determined by their specific within-host immune-viral dynamics (Sun et al. (2016); Yeghiazarian et al. (2013)).

\section{Complexity of multi-scale models}

Multi-scale HIV immunoepidemiological models have higher complexity in comparison to singlescale immune or epidemiology models (Mideo et al. (2008)). Thereby, the choice of immunoepidemiological models should be determined by problems with significant public health and clinical implications that can be addressed better by multi-scale models compared to single-scale models. 


\section{Clinical and public health relevant problems of HIV dynamics}

Table 11 illustrates the clinical and public health relevant problems of HIV virulence, co-infection, super infection, drug resistance and treatment dynamics that can be potentially addressed using multi-scale models. Since the viral load among infected individuals varies with time during the acute, latent and late stages of HIV infection, immunoepidemiological models account for the timevarying viral load within host and their impact on transmission between hosts. Co-infection among HIV-infected individuals increases the average set-point of viral load in the population (Cuadros \& García-Ramos (2012)). Super-infection of multiple HIV strains leads to oscillations in the population level which do not occur in the absence of super-infection; this effect is only observed using the multi-scale immunoepidemiological model (Martcheva \& Li (2013)). The emergence of drug resistance within hosts impacts the optimal coverage levels of drug-sensitive treatment at the population level (Saenz \& Bonhoeffer (2013)). Immunoepidemiological models can account for treatment initiation, compliance and interruption behavior among HIV-positive individuals as well as pre-exposure prophylaxis of high-risk HIV-negative individuals, and their impact on emergence of drug resistance in the population. The new knowledge gained from analysis of HIV immunoepidemiological dynamics add value in improving clinical and public health interventions for prevention and control of HIV epidemics.

\section{Limitations}

We reviewed English language articles on HIV immunoepidemiological models that were referenced in the PubMed database. The dynamics of the HIV immunoepidemiological models are dependent on the selection of parameters, and the coupling mechanisms of within-host immune-viral dynamics and between-host transmission dynamics. Verification and validation of HIV immunoepidemiological models (and multi-scale models in general) with empirical data is a challenge to be addressed in future studies. Also, the selection of optimal layers from the genomic, molecular, cellular, and organ levels at the micro-biological scale to the individual, family, community, national, and global levels at the macro-social scale is a challenge that need be addressed well in 
future studies.

\section{Conclusion}

HIV immunoepidemiological models combine the immune-viral dynamics at the within-host immunological scale with the transmission dynamics at the between-host epidemiological scale to analyze HIV dynamics of a single strain infection, co-infection, super-infection, evolution, drug resistance, and treatment protocols in heterogeneous populations. Based on our understanding of synergistic dynamics of HIV at the individual and population scales, we should select the optimal layers of analysis from micro-biological to macro-social levels for multi-scale models to identify and improve solutions to clinical and public health relevant problems of HIV dynamics. 


\section{References}

Aaskov, J., Buzacott, K., Thu, H. M., Lowry, K., \& Holmes, E. C. (2006). Long-term transmission of defective rna viruses in humans and aedes mosquitoes. Science, 311(5758), 236238. Retrieved from http://science.sciencemag.org/content/311/5758/236 doi: 10.1126/science. 1115030

Abu-Raddad, L. J., Magaret, A. S., Celum, C., Wald, A., Longini, I. M., Jr., Self, S. G., \& Corey, L. (2008). Genital herpes has played a more important role than any other sexually transmitted infection in driving HIV prevalence in Africa. PLoS ONE, 3(5), e2230. Retrieved 201506-27, from http://dx.plos.org/10.1371/journal.pone.0002230 doi: 10.1371/journal.pone. 0002230

Akpa, O. M., \& Oyejola, B. A. (2010). Modeling the transmission dynamics of HIV/AIDS epidemics: An introduction and a review. J. Infect. Dev. Ctries., 4(10), 597-608.

Anderson, R. M., \& May, R. M. (1992). Infectious diseases of humans: Dynamics and control. OUP Oxford.

Attia, S., Egger, M., Müller, M., Zwahlen, M., \& Low, N. (2009). Sexual transmission of HIV according to viral load and antiretroviral therapy: Systematic review and meta-analysis. AIDS, 23(11), 1397-1404. Retrieved 2015-09-02, from http://www.ncbi.nlm.nih.gov/pubmed/19381076 doi: 10.1097/QAD.0b013e32832b7dca

Banks, H. T., Davidian, M., Hu, S., Kepler, G. M., \& Rosenberg, E. (2008). Modeling HIV immune response and validation with clinical data. Journal of Biological Dynamics, 2(4), 357-385. Retrieved 2015-08-06, from http://www.ncbi.nlm.nih.gov/pmc/articles/PMC2689816/ doi: 10.1080/17513750701813184

Callaway, D. S., \& Perelson, A. S. (2002). HIV-1 infection and low steady state viral loads. Bulletin of Mathematical Biology, 64(1), 29-64. Retrieved 2015- 
06-21, from http://link.springer.com/article/10.1006/bulm.2001.0266 doi: 10.1006/bulm.2001.0266

Cassels, S., Clark, S. J., \& Morris, M. (2008). Mathematical models for HIV transmission dynamics: Tools for social and behavioral science research. Journal of Acquired Immune Deficiency Syndromes, 47(Suppl 1), S34-39. doi: 10.1097/QAI.0b013e3181605da3

Cohen, J. (2011). HIV treatment as prevention. Science, 334(6063), 1628-1628. Retrieved 201509-02, from http://www. sciencemag.org/content/334/6063/1628 doi: 10.1126/science.334.6063.1628

Cuadros, D. F., Crowley, P. H., Augustine, B., Stewart, S. L., \& García-Ramos, G. (2011). Effect of variable transmission rate on the dynamics of HIV in sub-saharan Africa. BMC Infectious Diseases, 11, 216. doi: 10.1186/1471-2334-11-216

Cuadros, D. F., \& García-Ramos, G. (2012). Variable effect of co-infection on the HIV infectivity: Within-host dynamics and epidemiological significance. Theoretical Biology and Medical Modelling, 9(1), 9. Retrieved 2014-09-19, from http://www.tbiomed.com/content/9/1/9/abstract doi: 10.1186/1742-4682-9-9

Curran, J. W., Morgan, W. M., Hardy, A. M., Jaffe, H. W., Darrow, W. W., \& Dowdle, W. R. (1985). The epidemiology of AIDS: Current status and future prospects. Science, 229(4720), 1352-1357. Retrieved 2015-06-13, from http: //www. jstor.org/stable/1695452

De Boer, R. J., \& Perelson, A. S. (1998). Target cell limited and immune control models of HIV infection: A comparison. Journal of Theoretical Biology, 190(3), 201-214. Retrieved 2015-08-06, from http://wWw.sciencedirect.com/science/article/pii/S0022519397905488 doi: 10.1006/jtbi.1997.0548

DebRoy, S., \& Martcheva, M. (2008). Immuni-epidemiology and HIV-AIDS: A modeling perspective. In Mathematical Biology Research Trends (pp. 175-192). Nova Science Publishers. 
Doekes, H. M., Fraser, C., \& Lythgoe, K. A. (2017, 01). Effect of the latent reservoir on the evolution of HIV at the within- and between-host levels. PLOS Computational Biology, 13(1), 1-27. Retrieved from https://doi.org/10.1371/journal.pcbi.1005228 doi: 10.1371/journal.pcbi. 1005228

Feng, Z., Velasco-Hernandez, J., Tapia-Santos, B., \& Leite, M. C. A. (2011). A model for coupling within-host and between-host dynamics in an infectious disease. Nonlinear Dyn, 68(3), 401-411. Retrieved 2015-02-11, from http://link. springer.com/article/10.1007/s11071-011-0291-0 doi: 10.1007/s11071-011-0291-0

Fraser, C., Hollingsworth, T. D., Chapman, R., Wolf, F. d., \& Hanage, W. P. (2007). Variation in HIV-1 set-point viral load: Epidemiological analysis and an evolutionary hypothesis. Proceedings of the National Academy of Sciences, 104(44), 17441-17446. Retrieved 2015-08-08, from http: //wWw . pnas.org/content/104/44/17441 doi: 10.1073/pnas.0708559104

Gog, J. R., Pellis, L., Wood, J. L. N., McLean, A. R., Arinaminpathy, N., \& Lloyd-Smith, J. O. (2015). Seven challenges in modeling pathogen dynamics within-host and across scales. Epidemics, 10, 45-48. Retrieved 2015-08-08, from http://www. sciencedirect.com/science/article/pii/S1755436514000589 doi: 10.1016/j.epidem.2014.09.009

Haberman, S. (1990). Actuarial review of models for describing and predicting the spread of HIV infection and AIDS. Journal of the Institute of Actuaries (1886-1994), 117(2), 319-405. Retrieved 2015-08-06, from http: //www . jstor .org/stable/41140975

Hamers, R. L., Wallis, C. L., Kityo, C., Siwale, M., Mandaliya, K., Conradie, F., .. others (2011). Hiv-1 drug resistance in antiretroviral-naive individuals in sub-saharan africa after rollout of antiretroviral therapy: a multicentre observational study. The Lancet infectious diseases, 11(10), $750-759$. 
Handel, A., \& Rohani, P. (2015). Crossing the scale from within-host infection dynamics to between-host transmission fitness: A discussion of current assumptions and knowledge. Philosophical Transactions of the Royal Society of London B: Biological Sciences, 370(1675). Retrieved from http://rstb. royalsocietypublishing.org/content/370/1675/20140302 doi: 10.1098/rstb.2014.0302

Hellriegel, B. (2001). Immunoepidemiology-bridging the gap between immunology and epidemiology. Trends in Parasitology, 17(2), 102-106.

Ho, D. D., Neumann, A. U., Perelson, A. S., Chen, W., Leonard, J. M., \& Markowitz, M. (1995). Rapid turnover of plasma virions and CD4 lymphocytes in HIV-1 infection. Nature, 373(6510), 123-126. doi: $10.1038 / 373123 \mathrm{a} 0$

Hollingsworth, T. D., Anderson, R. M., \& Fraser, C. (2008). HIV-1 transmission, by stage of infection. J. Infect. Dis., 198(5), 687-693. doi: 10.1086/590501

Hosseini, I., \& Mac Gabhann, F. (2012). Multi-scale modeling of HIV infection in vitro and APOBEC3g-based anti-retroviral therapy. PLoS Comput Biol, 8(2), e1002371. Retrieved 201508-06, from http://dx.doi.org/10.1371/journal.pcbi.1002371 doi: 10.1371/journal.pcbi. 1002371

Hué, S., Gifford, R. J., Dunn, D., Fernhill, E., Pillay, D., \& UK Collaborative Group on HIV Drug Resistance. (2009). Demonstration of sustained drug-resistant human immunodeficiency virus type 1 lineages circulating among treatment-naive individuals. Journal of virology, 83(6), $2645-2654$.

Hyman, J. M., \& Ann Stanley, E. (1988). Using mathematical models to understand the AIDS epidemic. Mathematical Biosciences, 90(1-2), 415-473. doi: 10.1016/0025-5564(88)90078-8

Isham, V. (1988). Mathematical modelling of the transmission dynamics of HIV infection and AIDS: A review. Journal of the Royal Statistical Society. Series A (Statistics in Society), 
151(1), 5-49. Retrieved 2015-08-06, from http://www. jstor.org/stable/2982179 doi: $10.2307 / 2982179$

Kirschner, D. (1996). Using mathematics to understand HIV immune dynamics. Notices Amer. Math. Soc., 43, 191-202.

Kouyos, R. D., von Wyl, V., Hinkley, T., Petropoulos, C. J., Haddad, M., Whitcomb, J. M., ... the Swiss HIV Cohort Study (2011, 11). Assessing predicted hiv-1 replicative capacity in a clinical setting. PLOS Pathogens, 7(11), 1-5. Retrieved from https://doi.org/10.1371/journal.ppat.1002321 doi: 10.1371/journal.ppat.1002321

Kublin, J. G., Patnaik, P., Jere, C. S., Miller, W. C., Hoffman, I. F., Chimbiya, N., ... Molyneux, M. E. (2005). Effect of plasmodium falciparum malaria on concentration of hiv-1-rna in the blood of adults in rural malawi: a prospective cohort study. The Lancet, 365(9455), 233-240.

Lemey, P., Rambaut, A., \& Pybus, O. G. (2006). HIV evolutionary dynamics within and among hosts. /bfAIDS Reviews, 8(3), 125-140. Retrieved 2014-09-09, from http://www.aidsreviews.com/audita.asp?d=2006 $8_{31} 25-140 . p d f t=D w=$ /resumen.aspq $=i d=897$ indice $=200683$

Levine, B. L., Humeau, L. M., Boyer, J., MacGregor, R.-R., Rebello, T., Lu, X., .. others (2006). Gene transfer in humans using a conditionally replicating lentiviral vector. Proceedings of the National Academy of Sciences, 103(46), 17372-17377.

Lythgoe, K. A., Pellis, L., \& Fraser, C. (2013). Is HIV short-sighted? Insights from a multistrain nested model. Evolution, 67(10), 2769-2782. Retrieved 2014-0919, from http://onlinelibrary.wiley.com/doi/10.1111/evo.12166/abstract doi: 10.1111/evo.12166

Martcheva, M., \& Li, X.-Z. (2013). Linking immunological and epidemiological dynamics of HIV: The case of super-infection. J Biol Dyn, 7(1), 161-182. doi: 10.1080/17513758.2013.820358 
McLean, A. R. (1993). The balance of power between HIV and the immune system. Trends in Microbiology, 1(1), 9-13.

Metzger, V. T., Lloyd-Smith, J. O., \& Weinberger, L. S. (2011, 03). Autonomous targeting of infectious superspreaders using engineered transmissible therapies. PLOS Computational Biology, 7(3), 1-12. Retrieved from https://doi.org/10.1371/journal.pcbi.1002015 doi: 10.1371/journal.pcbi.1002015

Mideo, N., Alizon, S., \& Day, T. (2008). Linking within- and between-host dynamics in the evolutionary epidemiology of infectious diseases. Trends Ecol. Evol. (Amst.), 23(9), 511-517. doi: $10.1016 / j$.tree.2008.05.009

Modjarrad, K., \& Vermund, S. H. (2010). Effect of treating co-infections on hiv-1 viral load: a systematic review. The Lancet infectious diseases, 10(7), 455-463.

Moher, D., Liberati, A., Tetzlaff, J., \& Altman, D. G. (2009). Preferred reporting items for systematic reviews and meta-analyses: The PRISMA statement. $\quad P L O S$ Med, 151(4), 264-269. Retrieved 2014-09-19, from http://dx .doi .org/10.7326/0003-4819-151-4-200908180-00135 doi: 10.1371/journal.pmed.1000097

Nowak, M., \& May, R. M. (2000). Virus dynamics : Mathematical principles of immunology and virology. Oxford University Press, UK.

Pepin, K. M., Volkov, I., Banavar, J. R., Wilke, C. O., \& Grenfell, B. T. (2010). Phenotypic differences in viral immune escape explained by linking within-host dynamics to host-population immunity. J. Theor. Biol., 265(4), 501-510. doi: 10.1016/j.jtbi.2010.05.036

Perelson, A. S., Neumann, A. U., Markowitz, M., Leonard, J. M., \& Ho, D. D. (1996). HIV1 dynamics in vivo: Virion clearance rate, infected cell life-span, and viral generation time. Science, 271(5255), 1582-1586. 
Perelson, A. S., \& Ribeiro, R. M. (2013). Modeling the within-host dynamics of HIV infection. BMC Biology, 11(1), 96. Retrieved 2015-08-06, from http://www . biomedcentral.com/1741-7007/11/96/abstract doi: 10.1186/17417007-11-96

Reddy, B., \& Yin, J. (1999). Quantitative intracellular kinetics of HIV type 1. AIDS Research and Human Retroviruses, 15(3), 273-283. Retrieved 2015-0929, from http://online. liebertpub.com/doi/abs/10.1089/088922299311457 doi: $10.1089 / 088922299311457$

Rong, L., Feng, Z., \& Perelson, A. S. (2007, Aug 01). Emergence of hiv-1 drug resistance during antiretroviral treatment. Bulletin of Mathematical Biology, 69(6), 2027-2060. Retrieved from https://doi.org/10.1007/s11538-007-9203-3 doi: 10.1007/s11538-007-9203-3

Saenz, R. A., \& Bonhoeffer, S. (2013). Nested model reveals potential amplification of an HIV epidemic due to drug resistance. Epidemics, 5(1), 34-43. Retrieved 2015-01-31, from http://www. sciencedirect.com/science/article/pii/S1755436512000527 doi: 10.1016/j.epidem.2012.11.002

Shen, M., Xiao, Y., \& Rong, L. (2015). Global stability of an infectionage structured HIV-1 model linking within-host and between-host dynamics. Mathematical Biosciences, 263, 37 - 50. Retrieved from http://www. sciencedirect.com/science/article/pii/S0025556415000358 doi: http://dx.doi.org/10.1016/j.mbs.2015.02.003

Spouge, J. L., Shrager, R. I., \& Dimitrov, D. S. (1996). HIV-1 infection kinetics in tissue cultures. Mathematical Biosciences, 138(1), 1-22. Retrieved 2015-09-29, from http://www. sciencedirect.com/science/article/pii/S0025556496000648 doi: 10.1016/S0025-5564(96)00064-8 
Stafford, M. A., Lawrence, C., Cao, Y., Daar, E. S., Ho, D. D., \& Perelson, A. S. (2000). Modeling plasma virus concentration during primary HIV infection. Journal of Theoretical Biology, 203(3), 285-301. Retrieved 2015-06-21, from http://wWw. sciencedirect.com/science/article/pii/S0022519300910762 doi: 10.1006/jtbi.2000.1076

Sun, X., Xiao, Y., Tang, S., Peng, Z., Wu, J., \& Wang, N. (2016, 03). Early HAART initiation may not reduce actual reproduction number and prevalence of MSM infection: Perspectives from coupled within- and between-host modelling studies of Chinese MSM populations. PLOS ONE, 11(3), 1-21. Retrieved from https://doi.org/10.1371/journal.pone.0150513 doi: 10.1371/journal.pone.0150513

Wang, H., Wolock, T. M., Carter, A., Nguyen, G., Kyu, H. H., Gakidou, E., .. Murray, C. J. L. (2016). Estimates of global, regional, and national incidence, prevalence, and mortality of HIV, 1980-2015: The global burden of disease study 2015. The Lancet HIV ,3(8), e361-e387.

When To Start Consortium, Sterne, J. A. C., May, M., Costagliola, D., de Wolf, F., Phillips, A. N., ... Cole, S. R. (2009, 18 April). Timing of initiation of antiretroviral therapy in AIDS-free HIV-1-infected patients: a collaborative analysis of 18 HIV cohort studies. Lancet, 373(9672), $1352-1363$.

Yeghiazarian, L., Cumberland, W. G., \& Yang, O. O. (2013). A stochastic multi-scale model of HIV-1 transmission for decision-making: Application to a MSM population. PLOS ONE, 8(11). Retrieved 2015-09-02, from http://www.ncbi.nlm.nih.gov/pmc/articles/PMC3841178/ doi: 10.1371/journal.pone. 0070578

Zaidi, J., Grapsa, E., Tanser, F., Newell, M.-L., \& Bärnighausen, T. (2013). Dramatic increases in hiv prevalence after scale-up of antiretroviral treatment: a longitudinal population-based hiv surveillance study in rural kwazulu-natal. AIDS (London, England), 27(14), 2301. 
Zarrabi, N., Mancini, E., Tay, J., Shahand, S., \& Sloot, P. M. A. (2010). Modeling HIV-1 intracellular replication: Two simulation approaches. Procedia Computer Science, 1(1), 555-564. Retrieved 2015-09-29, from http://www.sciencedirect.com/science/article/pii/S1877050910000608 doi: 10.1016/j.procs. 2010.04 .059 
587

588

\section{FIGURE LEGENDS}

\section{Figure 1}

Within-host immune-viral dynamics and between-host transmission dynamics of HIV. HIV spreads in the population from infected individuals to susceptibles through sexual contact, intravenous drug use, blood transfusion and mother-to-child vertical transmission. HIV immune-viral dynamics determine the time-varying viral load within each infected individual.

\section{Figure 2}

PRISMA flow-diagram. PRISMA (Preferred Reporting Items for Systematic Reviews and MetaAnalyses) flow-diagram of articles' identification, screening, eligibility and inclusion in the systematic review. A total of 9 studies are included in this systematic review of multi-scale immunoepidemiological modeling of within-host and between-host HIV dynamics. 
Figure 1

Figure 1: Within-host immune-viral dynamics and between-host transmission dynamics of HIV.

HIV spreads in the population from infected individuals to susceptibles through sexual contact, intravenous drug use, blood transfusion and mother-to-child vertical transmission. HIV immune-viral dynamics determine the time-varying viral load within each infected individual.

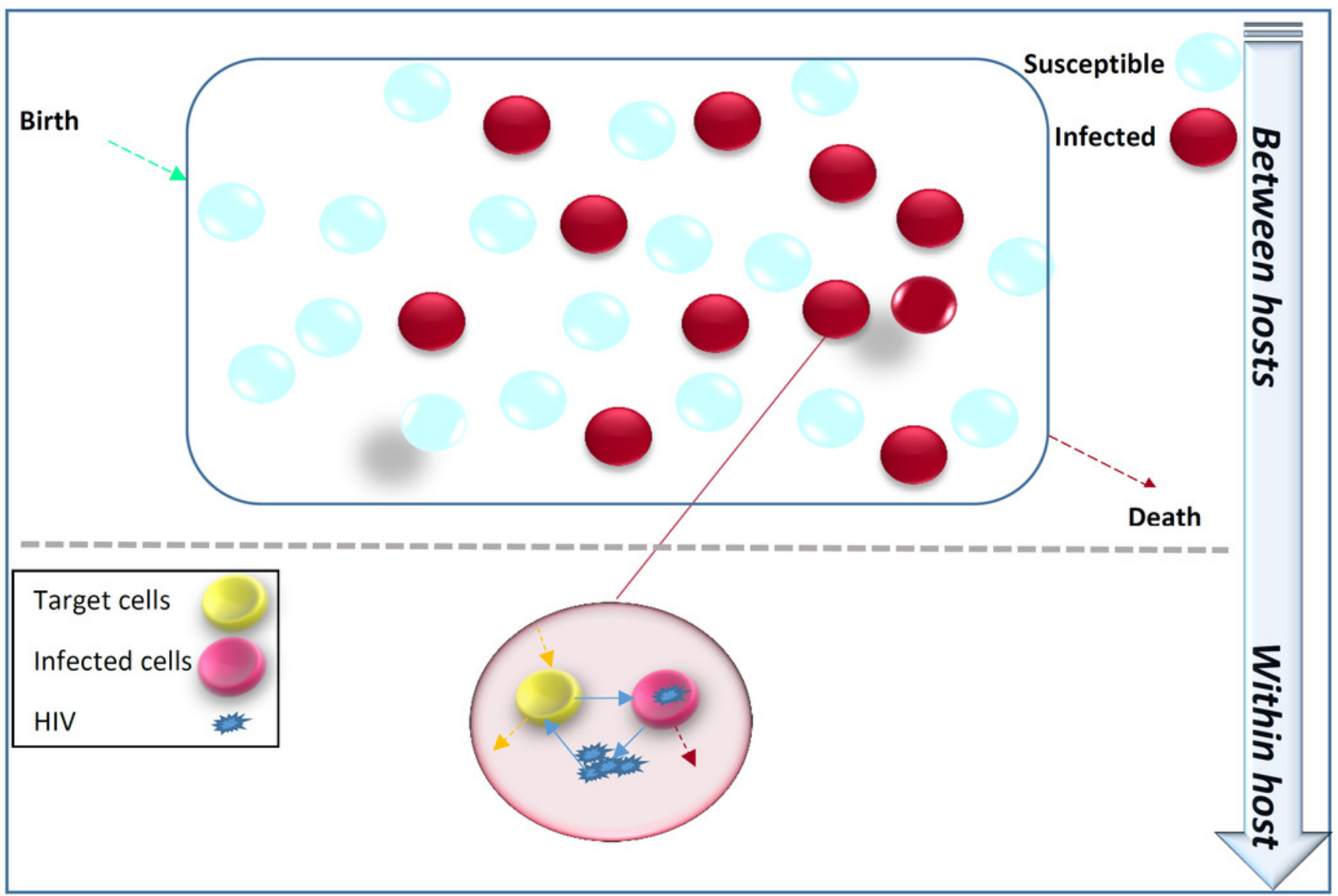


Figure 2

Figure 2: PRISMA flow-diagram.

PRISMA (Preferred Reporting Items for Systematic Reviews and Meta-Analyses) flow-diagram of articles' identification, screening, eligibility and inclusion in the systematic review. A total of 9 studies are included in this systematic review of multi-scale immunoepidemiological modeling of within-host and between-host HIV dynamics.
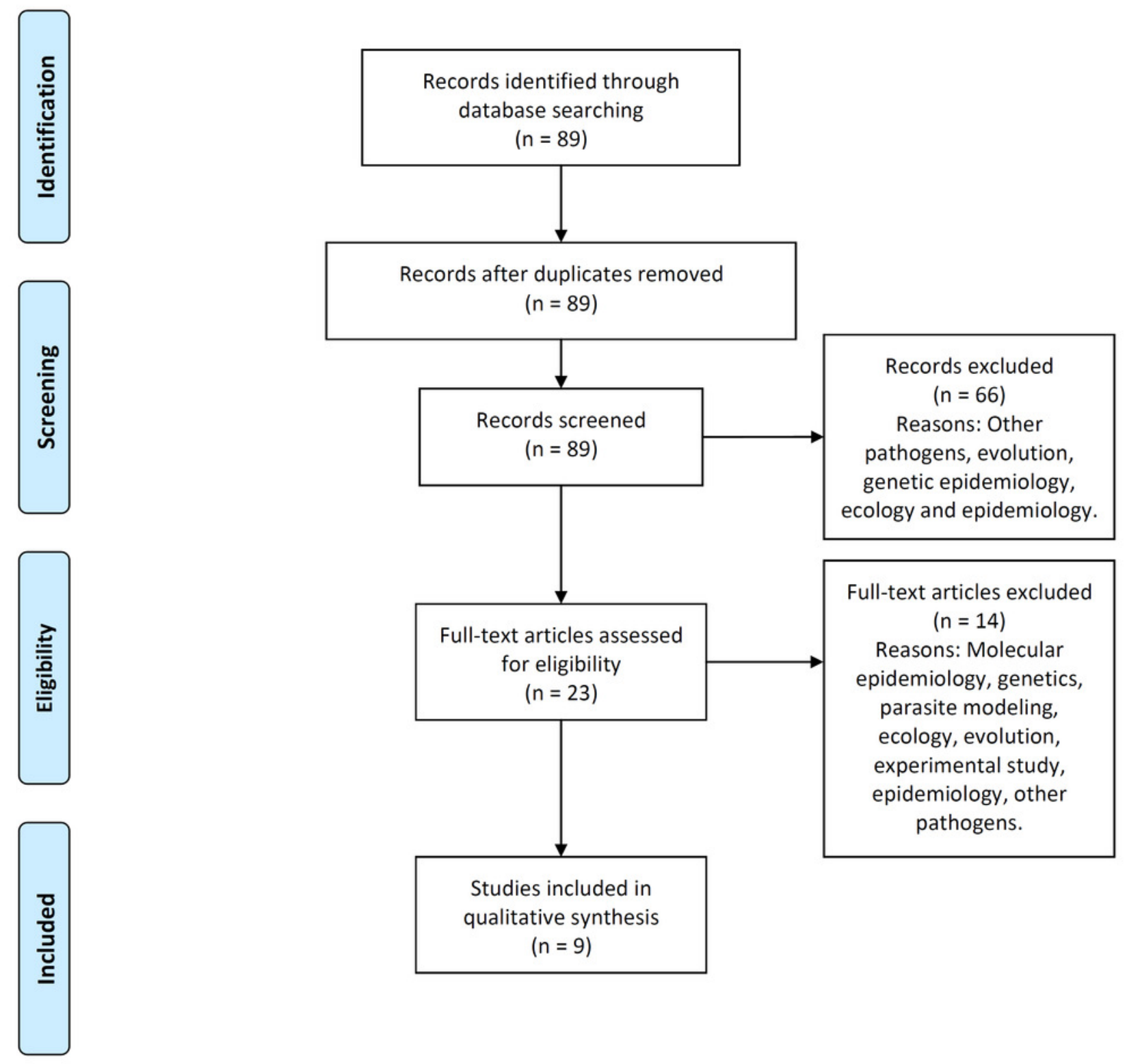


\section{Table $\mathbf{1}$ (on next page)}

Table 1: Characteristics of HIV immunoepidemiological modeling studies.

The study topic, objective, model implementation, immunoepidemiological link between within-host and between-host models, and inferences of the studies included in the systematic review are summarized. 
Table 1: Characteristics of HIV immunoepidemiological modeling studies. The study topic, objective, model implementation, immunoepidemiological link between within-host and between-host models, and inferences of the studies included in the systematic review are summarized.

\begin{tabular}{|c|c|c|c|c|c|}
\hline Study & Topic & Objective & Implementation & Immunoepidemiological link & Inferences \\
\hline Martcheva & Super- & How does HIV & Partial differen- & Transmission rate between hosts & In certain cases, decreasing viral load can cause \\
\hline $\begin{array}{ll}\& & \mathrm{Li} \\
(2013) & \end{array}$ & infection & $\begin{array}{l}\text { super-infection } \\
\text { affect population } \\
\text { dynamics? }\end{array}$ & tial equations & $\begin{array}{l}\text { and death rate of individuals de- } \\
\text { pend on viral load within host } \\
\text { over time. }\end{array}$ & $\begin{array}{l}\text { higher prevalence of HIV since infected indi- } \\
\text { viduals may live longer; oscillations at popula- } \\
\text { tion level do not occur in superinfection, con- } \\
\text { trasting previous studies that did not use linked } \\
\text { models. }\end{array}$ \\
\hline $\begin{array}{l}\text { Saenz \& } \\
\text { Bonhoeffer } \\
(2013)\end{array}$ & $\begin{array}{l}\text { Drug re- } \\
\text { sistance }\end{array}$ & $\begin{array}{l}\text { How do the } \\
\text { dynamics of } \\
\text { drug-sensitive } \\
\text { and drug-resistant } \\
\text { HIV strains within } \\
\text { hosts affect the } \\
\text { prevalence of } \\
\text { drug-resistant } \\
\text { strains in the } \\
\text { population? }\end{array}$ & $\begin{array}{l}\text { Partial differen- } \\
\text { tial equations }\end{array}$ & $\begin{array}{l}\text { Transmission rate between hosts } \\
\text { depends on viral load within host } \\
\text { over time. }\end{array}$ & $\begin{array}{l}\text { Increasing early initiation and coverage de- } \\
\text { creases total prevalence upto an optimal treat- } \\
\text { ment coverage level but increases incidence and } \\
\text { prevalence of drug resistant infections; above } \\
\text { the optimal treatment coverage level, number of } \\
\text { infections may not decrease in the long term and } \\
\text { can even increase. }\end{array}$ \\
\hline $\begin{array}{l}\text { Lythgoe et } \\
\text { al. (2013) }\end{array}$ & Evolution & $\begin{array}{l}\text { How does com- } \\
\text { petition between } \\
\text { strains within-host } \\
\text { affect evolution of } \\
\text { HIV virulence? }\end{array}$ & $\begin{array}{l}\text { Integro- } \\
\text { differential } \\
\text { equations with } \\
\text { delay }\end{array}$ & $\begin{array}{l}\text { Strain-specific infectivity rate be- } \\
\text { tween hosts depends on frequency } \\
\text { of strains within-host. }\end{array}$ & $\begin{array}{l}\text { Small rates of within-host evolution mod- } \\
\text { estly increase HIV virulence while maximiz- } \\
\text { ing transmission potential; high rates of within- } \\
\text { host evolution largely increase HIV virulence } \\
\text { but lower transmission potential. }\end{array}$ \\
\hline $\begin{array}{l}\text { Doekes et } \\
\text { al. }(2017)\end{array}$ & Evolution & $\begin{array}{l}\text { How does latent } \\
\text { reservoir of in- } \\
\text { fected CD4+ } \mathrm{T} \\
\text { cells affect the } \\
\text { types of strains } \\
\text { of HIV that will } \\
\text { evolve within and } \\
\text { between hosts? }\end{array}$ & $\begin{array}{l}\text { Integro- } \\
\text { differential } \\
\text { equations with } \\
\text { delay }\end{array}$ & $\begin{array}{l}\text { Strain-specific infectivity rate be- } \\
\text { tween hosts depends on frequency } \\
\text { of strain in actively infected } \\
\text { CD4+ T cells within-host. }\end{array}$ & $\begin{array}{l}\text { Relatively large latent reservoirs cause delay to } \\
\text { within-host evolutionary processes, which se- } \\
\text { lect for moderately virulent strains that opti- } \\
\text { mize transmission at the population level; with } \\
\text { no reservoir, highly virulent strains are selected } \\
\text { for within-host that do not optimize transmis- } \\
\text { sion at the population level. }\end{array}$ \\
\hline
\end{tabular}




\begin{tabular}{|c|c|c|c|c|c|}
\hline Study & Topic & Objective & Implementation & Immunoepidemiological link & Inferences \\
\hline $\begin{array}{l}\text { Cuadros } \\
\& \text { García- } \\
\text { Ramos } \\
(2012)\end{array}$ & $\begin{array}{l}\text { Co- } \\
\text { infection }\end{array}$ & $\begin{array}{l}\text { How does co- } \\
\text { infection affect the } \\
\text { HIV replication } \\
\text { capacity? }\end{array}$ & $\begin{array}{l}\text { Ordinary differ- } \\
\text { ential equations }\end{array}$ & $\begin{array}{l}\text { Transmission rate between hosts } \\
\text { depends on steady-state of viral } \\
\text { load within host. }\end{array}$ & $\begin{array}{l}\text { Impact of co-infection increases as average set- } \\
\text { point viral load of population increases. }\end{array}$ \\
\hline $\begin{array}{l}\text { Yeghiazarian } \\
\text { et al. } \\
(2013)\end{array}$ & ART & $\begin{array}{l}\text { How does the tim- } \\
\text { ing of antiretrovi- } \\
\text { ral therapy (ART) } \\
\text { in individuals af- } \\
\text { fect the spread of } \\
\text { HIV? }\end{array}$ & $\begin{array}{l}\text { Individual- } \\
\text { based model }\end{array}$ & $\begin{array}{l}\text { Transmission rate to each suscep- } \\
\text { tible partner depends on viral load } \\
\text { of infected individual. }\end{array}$ & $\begin{array}{l}\text { Beginning ART during acute infection is most } \\
\text { effective for reducing spread of HIV. }\end{array}$ \\
\hline $\begin{array}{l}\text { Shen et al. } \\
(2015)\end{array}$ & ART & $\begin{array}{l}\text { How does an- } \\
\text { tiretroviral therapy } \\
\text { (ART) affect HIV } \\
\text { prevalence? }\end{array}$ & $\begin{array}{l}\text { Partial differen- } \\
\text { tial equations }\end{array}$ & $\begin{array}{l}\text { Transmission rate depends on sat- } \\
\text { urated viral load within-host, and } \\
\text { varies between stages of infec- } \\
\text { tion. }\end{array}$ & $\begin{array}{l}\text { While ART decreases the viral load and infec- } \\
\text { tiousness of each infected host, in certain cases, } \\
\text { this can lead to higher spread of HIV through- } \\
\text { out the population because these infected indi- } \\
\text { viduals live longer; HIV can still be controlled } \\
\text { in these cases if drug effectiveness is high. }\end{array}$ \\
\hline $\begin{array}{l}\text { Metzger et } \\
\text { al. (2011) }\end{array}$ & TIPs & $\begin{array}{l}\text { How does intro- } \\
\text { duction of thera- } \\
\text { peutic interfering } \\
\text { particles (TIPs) af- } \\
\text { fect HIV preva- } \\
\text { lence? }\end{array}$ & $\begin{array}{l}\text { Ordinary differ- } \\
\text { ential equations }\end{array}$ & $\begin{array}{l}\text { Transmission rate between hosts } \\
\text { depends on steady-states of TIP } \\
\text { and HIV viral loads within-host. }\end{array}$ & $\begin{array}{l}\text { Deploying TIPs in even small numbers of in- } \\
\text { fected individuals reduces the prevalence of } \\
\text { HIV to low levels due to TIPs' ability to trans- } \\
\text { mit between hosts and target high-risk groups; } \\
\text { using TIPs reduces challenges of antiretroviral } \\
\text { therapy and vaccines, and complements them. }\end{array}$ \\
\hline
\end{tabular}




\section{Table 2 (on next page)}

Table 2: HIV infection with single strain.

Within-host layer of HIV multi-scale model with assumption of single strain HIV infection. The uninfected CD4+ T cells get infected by the free virions and produce HIV virus. CD4+ T cells have the constant reproduction and death rates. HIV induces death rate of infected cells. HIV population increases by production of virus by infected cells, and decreases because of the virus clearance and shedding rate. 


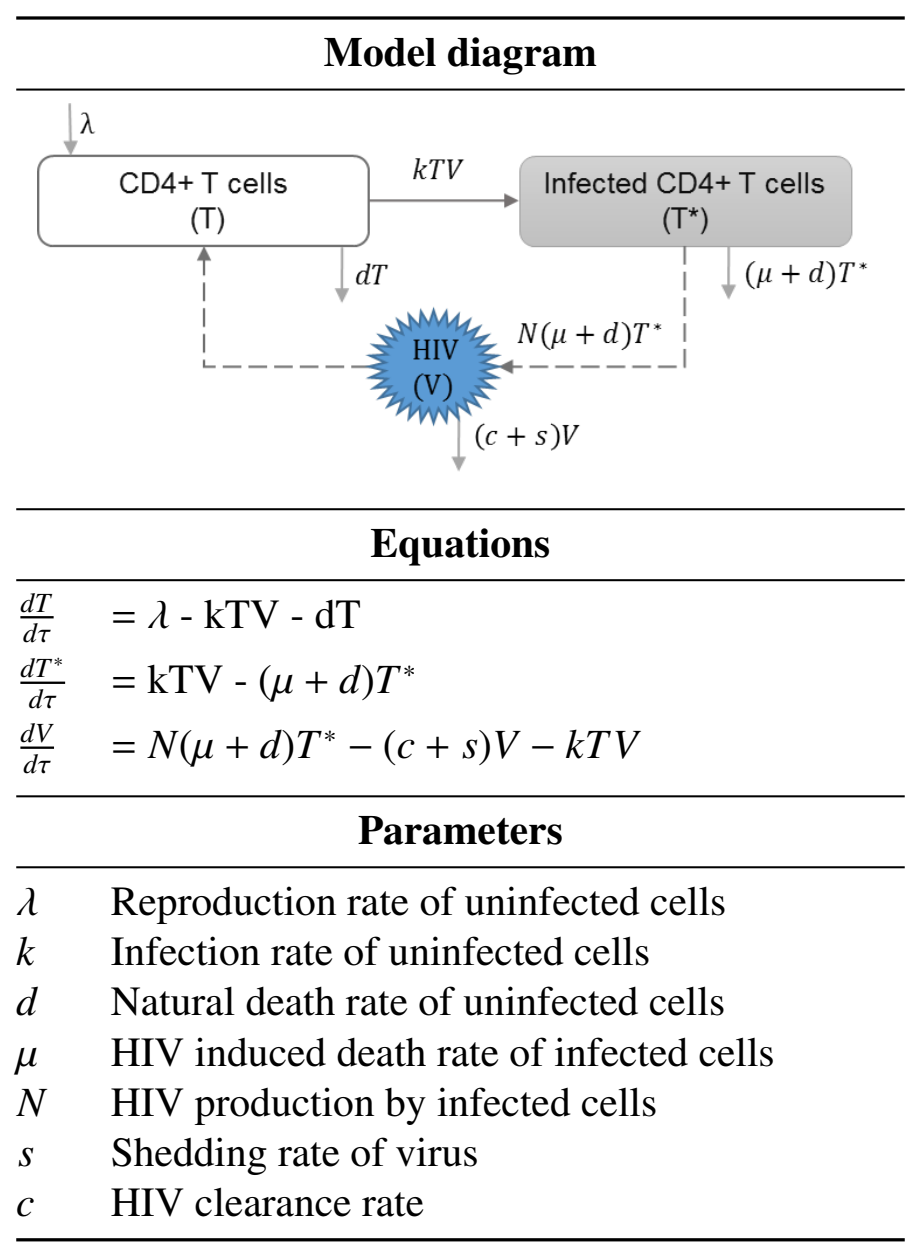

Table 2: HIV infection with single strain. Within-host layer of HIV multi-scale model with assumption of single strain HIV infection. The uninfected CD4+ T cells get infected by the free virions and produce HIV virus. CD4+ T cells have the constant reproduction and death rates. HIV induces death rate of infected cells. HIV population increases by production of virus by infected cells, and decreases because of the virus clearance and shedding rate. 


\section{Table 3(on next page)}

Table 3: HIV super-infection.

The within-host layer of HIV multi-scale model illustrates the impact of infection with multiple strains of HIV. This model includes the uninfected, infected target CD4+ T cells with different strains, and different strains of free HIV virions. An individual may get infected with drugresistant and/or drug-susceptible strains. Also, mutations may happen within-host leading to emergence of drug-resistant strains. 


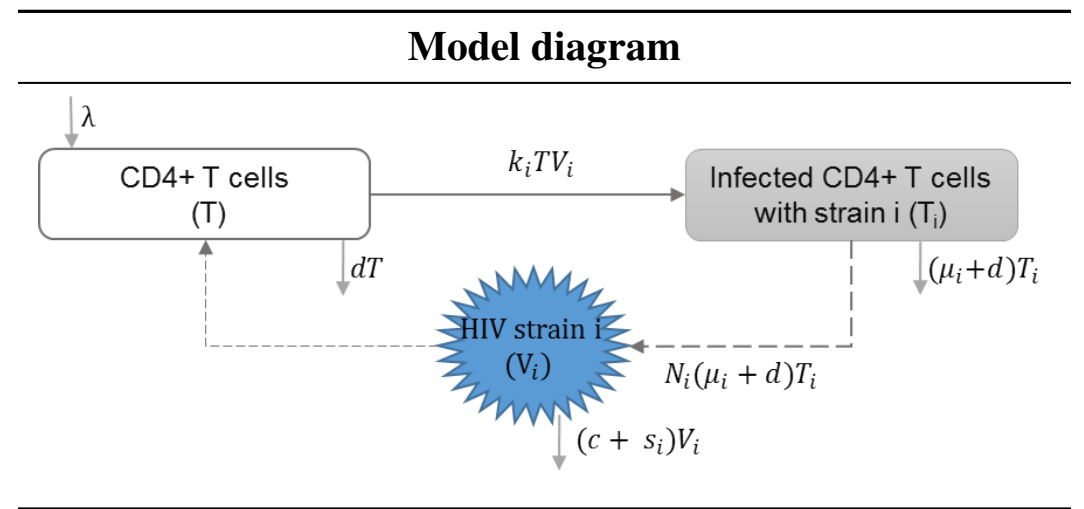

\section{Equations}

$$
\begin{array}{ll}
\overline{\frac{d T}{d \tau}} & =\lambda-k_{i} T V_{i}-d T \\
\frac{d T_{i}}{d \tau} & =k_{i} T V_{i}-\left(\mu_{i}+d\right) T_{i} \\
\frac{d V_{i}}{d \tau} & =N_{i}\left(\mu_{i}+d\right) T_{i}-\left(c+s_{i}\right) V_{i}-k_{i} T V_{i}
\end{array}
$$

\section{Parameters}

$\lambda \quad$ Reproduction rate of uninfected cells

$k_{i} \quad$ Infection rate of uninfected cells by virus strain $\mathrm{i}$

$\mu_{i} \quad$ HIV induced death rate of infected cell with strain $\mathrm{i}$

$N_{i} \quad$ HIV Production of virus i by infected cells

$s_{i} \quad$ Shedding rate of virus strain $\mathrm{i}$

$d \quad$ Natural death rate of uninfected cells

c HIV clearance rate

Table 3: HIV super-infection. The within-host layer of HIV multi-scale model illustrates the impact of infection with multiple strains of HIV. This model includes the uninfected, infected target CD4+ T cells with different strains, and different strains of free HIV virions. An individual may get infected with drug-resistant and/or drug-susceptible strains. Also, mutations may happen within-host leading to emergence of drug-resistant strains. 


\section{Table 4 (on next page)}

Table 4: HIV drug resistance.

The within-host layer of HIV multi-scale model illustrates the uninfected and infected target $\mathrm{CD} 4+\mathrm{T}$ cells, including drug-sensitive and drug-resistant strains. Mutations from drugsensitive to drug-resistant or drug-resistant to drug-sensitive strains are studied in this model, and the impact of treatment is also included. 


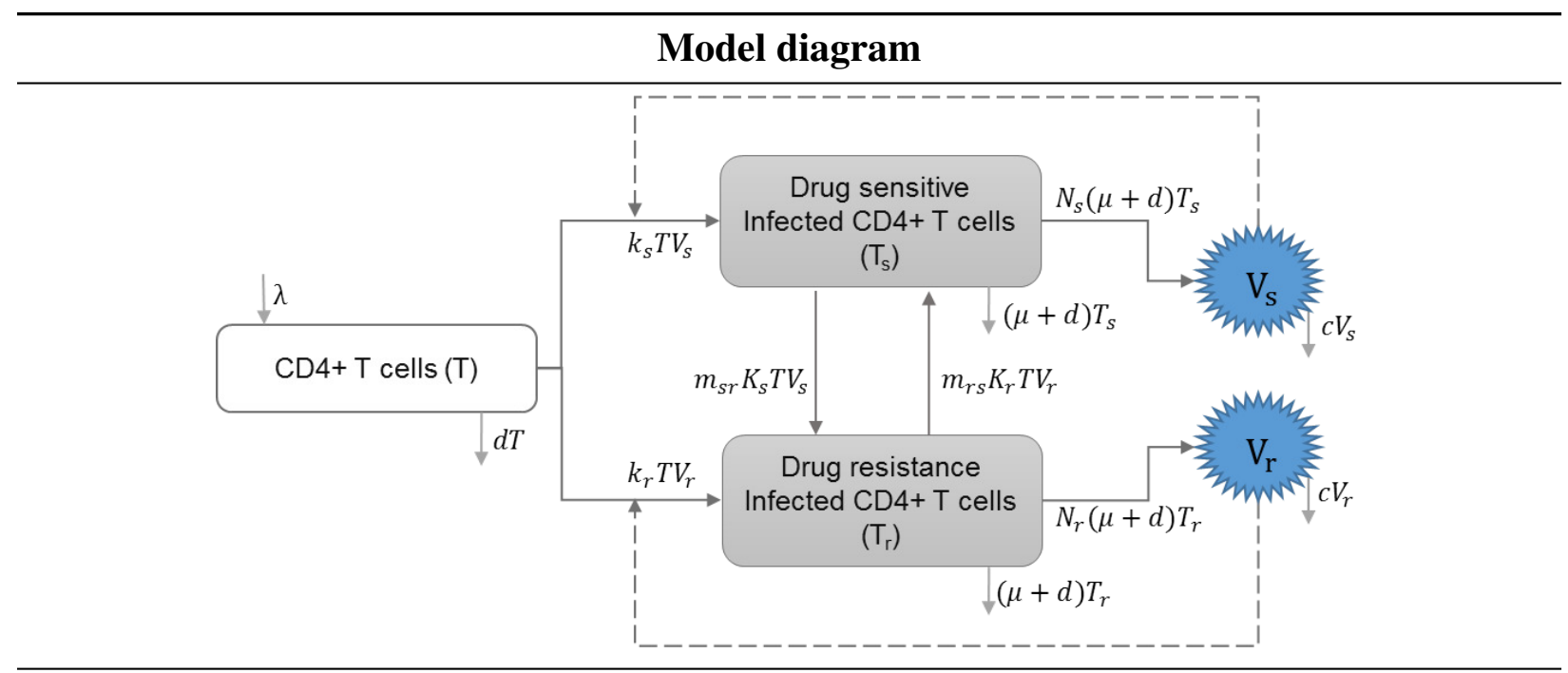

\section{Equations}

$\overline{\frac{d T}{d \tau}}=\lambda-\left(1-\epsilon_{r t}\right) k_{s} T V_{s}-\left(1-p_{r t} \epsilon_{r t}\right) k_{r} T V_{r}-d T$

$\frac{d T_{s}}{d \tau}=\left(1-m_{s r}\right)\left(1-\epsilon_{r t}\right) k_{s} T V_{s}+m_{r s}\left(1-p_{r t} \epsilon_{r t}\right) k_{r} T V_{r}-(\mu+d) T_{s}$

$\frac{d T_{r}}{d \tau} \quad=m_{s r}\left(1-\epsilon_{r t}\right) k_{s} T V_{s}+\left(1-m_{r s}\right)\left(1-p_{r t} \epsilon_{r t}\right) k_{r} T V_{r}-(\mu+d) T_{r}$

$\frac{d V_{s}}{d \tau}=\left(1-\epsilon_{p i}\right) N_{s}(\mu+d) T_{s}-c V_{s}$

$\frac{d V_{r}}{d \tau}=\left(1-p_{p i} \epsilon_{p i}\right) N_{r}(\mu+d) T_{r}-c V_{r}$

\section{Parameters}

$\lambda \quad$ Reproduction rate of uninfected cells

$k_{s} \quad$ infection rate of uninfected cells by drug-sensitive strain

$k_{r} \quad$ infection rate of uninfected cells by drug-resistant strain

$d \quad$ Natural death rate of uninfected cells

$\mu \quad$ HIV induced death rate of infected cells

$c \quad$ HIV clearance rate

$\epsilon_{r t} \quad$ Efficacy of reverse transcriptase inhibitor treatment

$\epsilon_{p i} \quad$ Efficacy of protease inhibitor treatment

$V_{s} \quad$ Drug sensitive strain of HIV

$V_{r} \quad$ Drug resistant strain of HIV

$m_{s r} \quad$ A proportion of infected cells with drug-sensitive strain that produce drug resistant virions

$m_{r s} \quad$ A proportion of infected cell with drug-resistant strain that produce drug sensitive virions

$p_{r t} \quad$ Relative rate of reverse transcriptase inhibitor efficacy for drug resistant strain

$p_{p i} \quad$ Relative rate of protease inhibitor efficacy for drug resistant strain

$N_{s} \quad$ Reproduction of HIV virus by drug-sensitive strain

$N_{r} \quad$ Reproduction of HIV virus by drug-resistant strain

Table 4: HIV drug resistance. The within-host layer of HIV multi-scale model illustrates the uninfected and infected target CD4+ T cells, including drug-sensitive and drug-resistant strains. Mutations from drug-sensitive to drug-resistant or drug-resistant to drug-sensitive strains are studied in this model, and the impact of treatment is also included. 


\section{Table 5 (on next page)}

Table 5: HIV co-infection.

The within-host layer of HIV multi-scale model illustrates the impact of co-infection. This model includes the uninfected and infected target CD4+ T cells, and free virions. Co-infection increases immune response and the infection rate of immune cells. Therefore, the set-point viral load is higher compared to the case of no co-infection. 


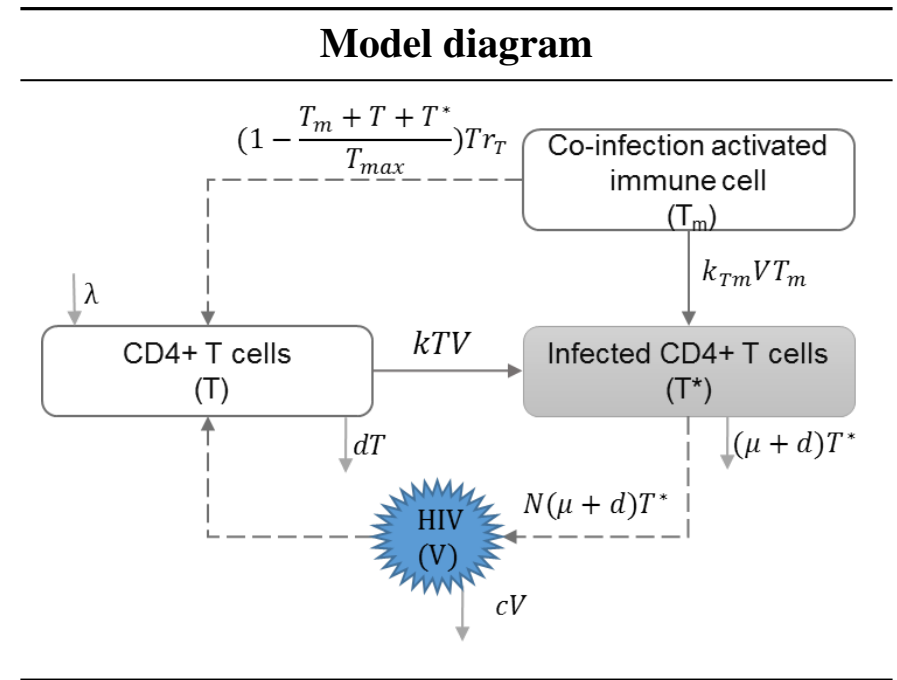

\begin{tabular}{ll}
\hline & \multicolumn{1}{c}{ Equations } \\
\hline$\frac{d T}{d \tau}$ & $=\lambda-k T V-d T+\left[1-\frac{T_{m}+T+T^{*}}{T_{\max }}\right] r_{T} T$ \\
$\frac{d T^{*}}{d \tau}$ & $=k T V-(\mu+d) T^{*}+k_{T m} V T_{m}$ \\
$\frac{d V}{d \tau}$ & $=N(\mu+d) T^{*}-c V$ \\
\hline & \multicolumn{1}{c}{ Parameters } \\
\hline$\lambda$ & Reproduction rate of uninfected cells \\
$k$ & Infection rate of uninfected cells \\
$d$ & Natural death rate of uninfected cells \\
$\mu$ & HIV induced death rate of infected cells \\
$N$ & HIV production by infected cells \\
$c$ & HIV clearance rate \\
$T_{m}$ & Activated immune cells against co-infection \\
$T_{m a x}$ & Maximum number of immune cells \\
$r_{T}$ & Growth rate of non-specific immune cells \\
$k_{T m}$ & Infection rate of co-infection \\
\hline
\end{tabular}

Table 5: HIV co-infection. The within-host layer of HIV multi-scale model illustrates the impact of co-infection. This model includes the uninfected and infected target CD4+ T cells, and free virions. Co-infection increases immune response and the infection rate of immune cells. Therefore, the set-point viral load is higher compared to the case of no co-infection. 


\section{Table 6(on next page)}

Table 6: Susceptible-Infected ( $S$ I) epidemic model.

The between-host layer of HIV multi-scale model illustrates the random mixing of susceptibles and infected individuals. Susceptibles get infected by the infected individuals. HIV transmission rate depends on the HIV viral load at the within-host scale. 


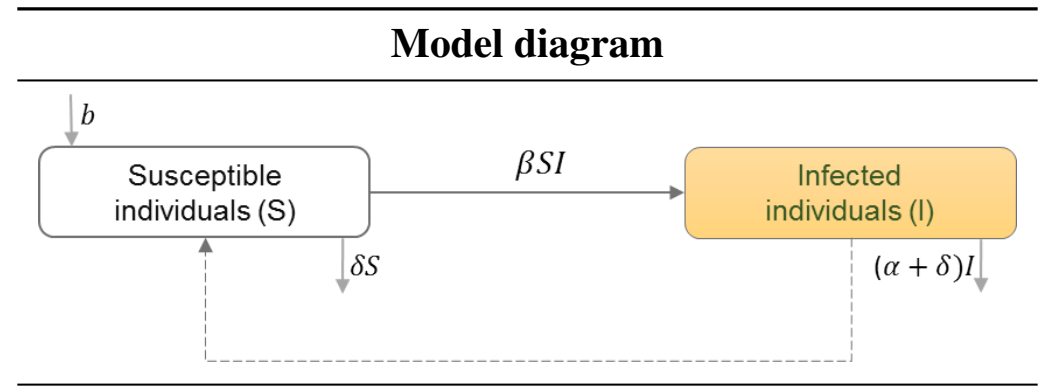

\section{Equations}

\begin{tabular}{ll}
\hline$\frac{d S}{d t}$ & $=b-\beta S I-\delta S$ \\
$\frac{d I}{d t}$ & $=\beta S I-(\alpha+\delta) I$
\end{tabular}

\section{Parameters}

$S \quad$ Number of individuals in the susceptible class

I Number of individuals in the infected class

$b \quad$ Natural birth rate in the population

$\beta \quad$ HIV transmission rate in the population

$\alpha \quad$ Disease induced mortality rate

$\delta \quad$ Natural death rate in the population

Table 6: Susceptible-Infected ( $S I$ ) epidemic model. The between-host layer of HIV multi-scale model illustrates the random mixing of susceptibles and infected individuals. Susceptibles get infected by the infected individuals. HIV transmission rate $(\beta)$ depends on the HIV viral load at the within-host scale. 


\section{Table 7 (on next page)}

Table 7: HIV drug resistance and treatment impact.

HIV transmission dynamics between drug-sensitive and drug-resistant infected individuals are illustrated. Infected individuals may get infected by the drug-sensitive or drug-resistant strains. A proportion $p$ of infected individuals get treatment, and among the infected individuals with drug-sensitive strains, a proportion $q$ of them develop drug resistance. 


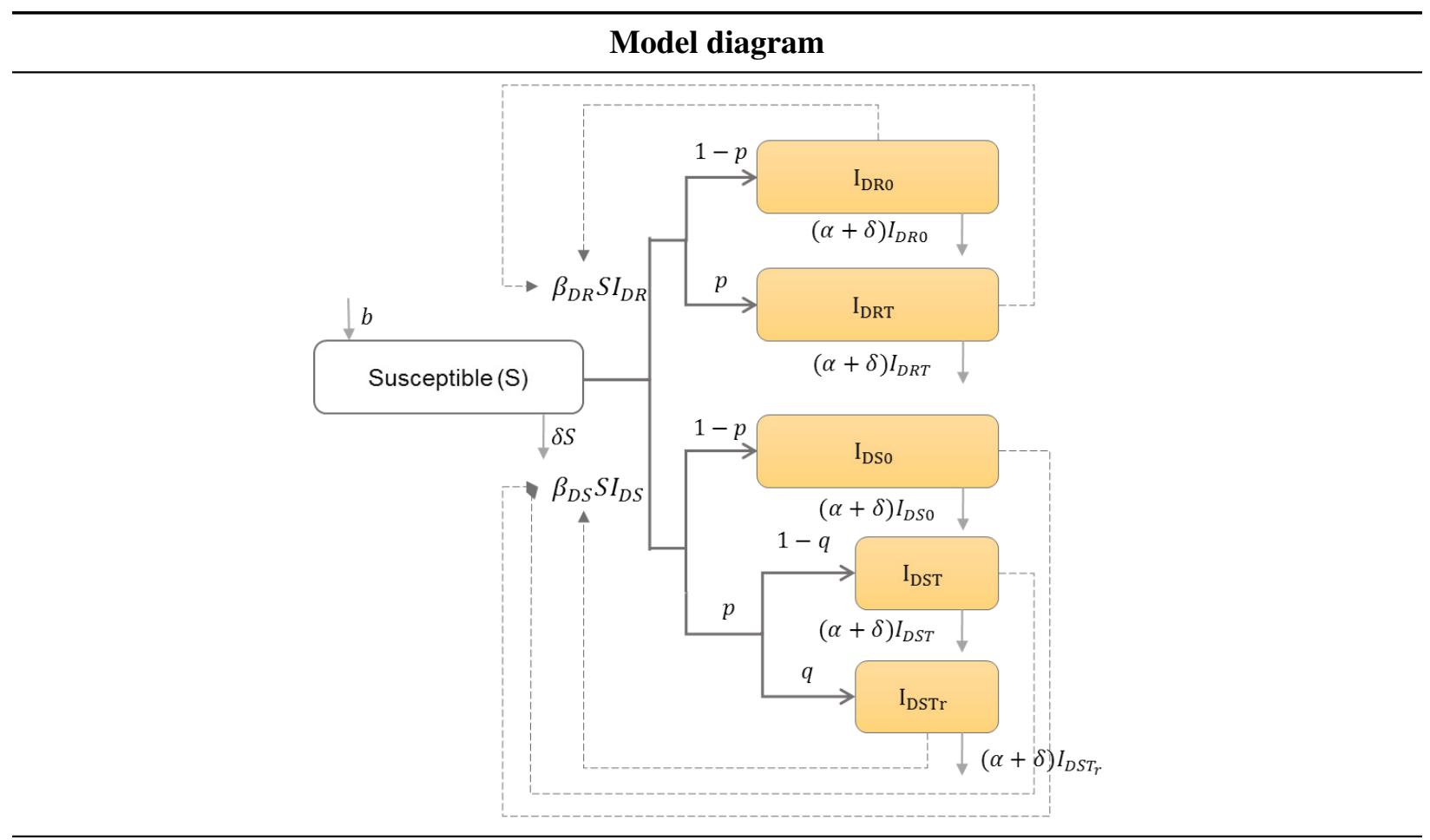

\section{Equations}

$$
\begin{array}{ll}
\frac{d S}{d t} & =b-\beta_{D R} S I_{D R}-\beta_{D S} S I_{D S}-\delta S \\
\frac{d I_{D R 0}}{d t} & =(1-p) \beta_{D R} S I_{D R}-(\alpha+\delta) I_{D R 0} \\
\frac{d I_{D R T}}{d t} & =p \beta_{D R} S I_{D R}-(\alpha+\delta) I_{D R T} \\
\frac{d I_{D S 0}}{d t} & =(1-p) \beta_{D S} S I_{D S}-(\alpha+\delta) I_{D S 0} \\
\frac{d I_{D S T}}{d t} & =p(1-q) \beta_{D S} S I_{D S}-(\alpha+\delta) I_{D S T} \\
\frac{d I_{D S T r}}{d t} & =p q \beta_{D S} S I_{D S}-(\alpha+\delta) I_{D S T r}
\end{array}
$$

\section{Parameters}

$b \quad$ Natural birth rate in the population

$I_{D R 0} \quad$ Number of individuals infected with drug-resistant strain and do not receive treatment

$I_{D R T} \quad$ Number of individuals infected with drug-resistant strain and receive treatment

$I_{D S 0} \quad$ Number of individuals infected with drug-sensitive strain and do not receive treatment

$I_{D S T} \quad$ Number of individuals infected with drug-sensitive strain and receive treatment

$I_{D S T r} \quad$ Number of individuals infected with drug-sensitive strain, receive treatment, and develop resistance

$\beta_{D R} \quad$ Drug-resistant HIV transmission rate in the population

$\beta_{D S} \quad$ Drug-sensitive HIV transmission rate in the population

$\alpha \quad$ HIV induced mortality rate

$\delta \quad$ Natural death rate in the population

$p \quad$ Proportion of infected individuals who receive treatment

$q \quad$ Proportion of infected individuals who receive treatment and develop resistance

$I_{D R} \quad I_{D R 0}+I_{D R T}$

$I_{D S} \quad I_{D S 0}+I_{D S T}+I_{D S T r}$

Table 7: HIV drug resistance and treatment impact. HIV transmission dynamics between drugsensitive and drug-resistant infected individuals are illustrated. Infected individuals may get infected by the drug-sensitive or drug-resistant strains. A proportion $p$ of infected individuals get treatment, and among the infected individuals 3 trug-sensitive strains, a proportion $q$ of them develop drug resistance. 


\section{Table 8 (on next page)}

Table 8: HIV evolution.

HIV transmission dynamics between infected individuals with different strains are illustrated. Infected individuals with strains $i$ may get infected with another strain $j$ and transmit the dominant strain of HIV. 


\section{Model diagram}

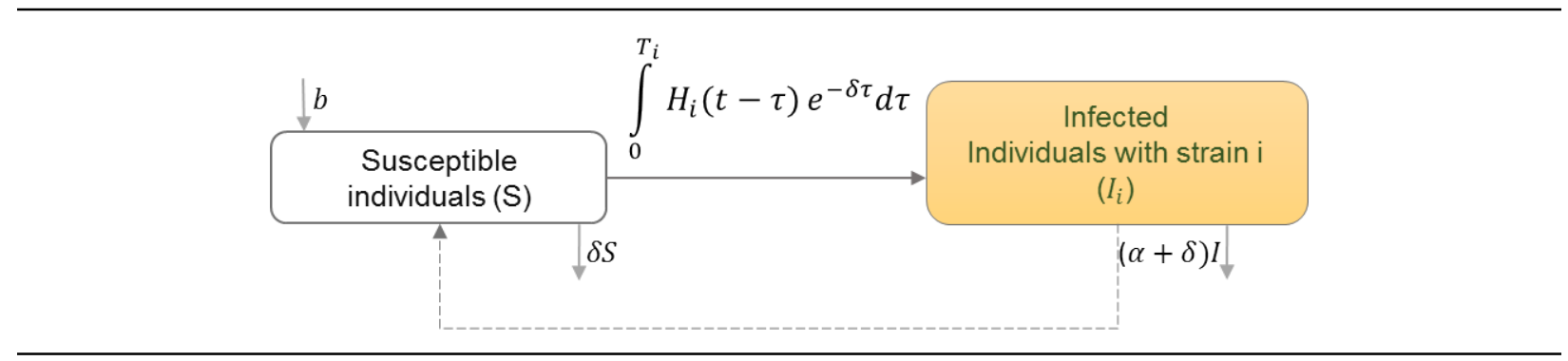

\section{Equations}

$$
\begin{aligned}
& S(t) \quad=b-\sum_{i=1}^{n} \int_{0}^{T_{i}} H_{i}(t-\tau) e^{-\delta \tau} d \tau \\
& I_{i}(t) \quad=\int_{0}^{T_{i}} H_{i}(t-\tau) e^{-\delta \tau} d \tau-(\alpha+\delta) I_{i} \\
& H_{i}(t) \quad=\frac{S(t)}{N(t)} \sum_{j=1}^{n} \int_{0}^{T_{i}} \beta_{i j}(\tau) H_{j}(t-\tau) e^{-\delta \tau} d \tau
\end{aligned}
$$

\section{Parameters}

$b \quad$ Natural birth rate in the population

$T_{i} \quad$ Time of death after initiation of infection

$H_{i} \quad$ The rate at which new type-i infection occur

$\delta \quad$ Natural mortality rate

$I_{i} \quad$ Number of individuals infected with strain $i$

$\beta_{i j} \quad$ Infectivity of strain $\mathrm{i}$ in a host originally infected with strain $\mathrm{j}$ at time $\tau$ since infection.

Table 8: HIV evolution. HIV transmission dynamics between infected individuals with different strains are illustrated. Infected individuals with strains $i$ may get infected with another strain $j$ and transmit the dominant strain of HIV. 


\section{Table 9 (on next page)}

Table 9: HIV and therapeutic interfering particles (TIPS).

HIV transmission dynamics between infected individuals with wild type of HIV and TIPs are illustrated. Individuals can get infected with wild type of HIV, TIPS, or both. Infected individuals can get reinfected with both types. 


\section{Model diagram}

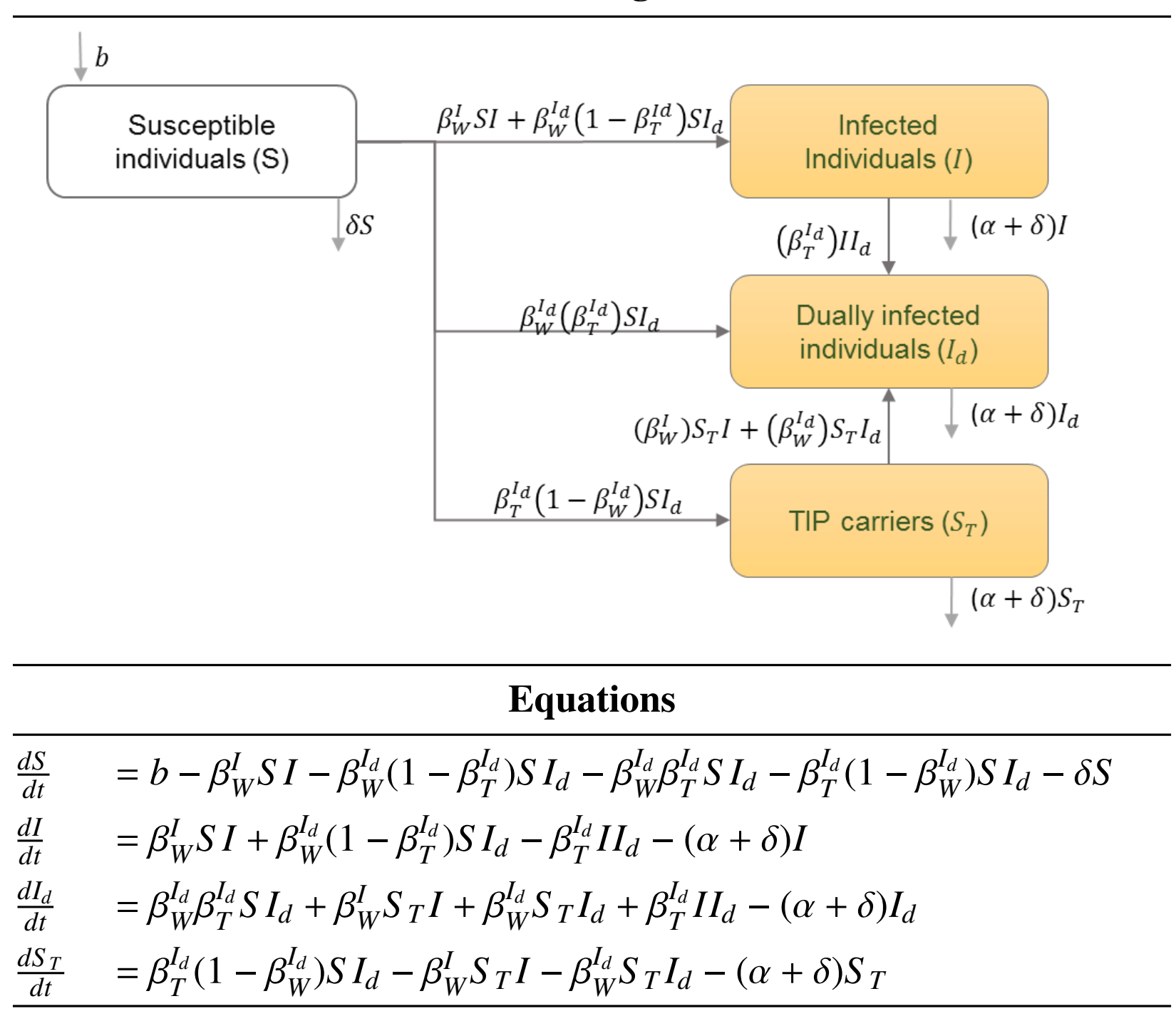

\section{Parameters}

$b \quad$ Natural birth rate in the population

I Number of infected individuals with only the wild type of HIV

$I_{d} \quad$ Individuals infected with both HIV and TIPs

$S_{T} \quad$ Individuals infected with only TIPs

$\beta_{W}^{I} \quad$ Transmission rate of wild type HIV from HIV infected individuals

$\beta_{W}^{I_{d}} \quad$ Transmission rate of wild type HIV from dually infected individuals

$\beta_{T}^{I_{d}} \quad$ Transmission rate of TIPs from dually infected individuals

Table 9: HIV and therapeutic interfering particles (TIPs). HIV transmission dynamics between infected individuals with wild type of HIV and TIPs are illustrated. Individuals can get infected with wild type of HIV, TIPS, or both. Infected individuals can get reinfected with both types. 


\section{Table $\mathbf{1 0}$ (on next page)}

Table 10: Coupling mechanism of within-host and between-host scales of HIV dynamics.

The within-host and between-host layers of HIV multi-scale model are linked using partial differential equations. The HIV viral immune dynamics model (see Table 2 ) determines the time-varying within-host viral load, which impacts the transmission rate. Another method to determine the HIV transmission rate is based on the viral load equilibrium. 


\section{Equations}

$\begin{array}{ll}\frac{d S}{d t} & =b-S \int_{0}^{\infty} \beta(\tau) I(\tau, t) d \tau-\delta S \\ \frac{\partial I}{\partial t}+\frac{\partial I}{\partial \tau} & =-m(V(\tau)) I(\tau, t) \\ I(0, t) & =S \int_{0}^{\infty} \beta(\tau) I(\tau, t) d \tau\end{array}$

Parameters

$S \quad$ Number of individuals in the susceptible class

$I(\tau, t) \quad$ Number of infected individuals structured by time since infection $(\tau)$

$b \quad$ Natural birth rate in the population

$\beta(\tau) \quad$ HIV transmission rate $(r . V(\tau))$

$m \quad$ Coefficient on dependence of induced mortality due to disease on the host viral load.

Table 10: Coupling mechanism of within-host and between-host scales of HIV dynamics. The within-host and between-host layers of HIV multi-scale model are linked using partial differential equations. The HIV viral immune dynamics model (see Table 2) determines the time-varying within-host viral load, which impacts the transmission rate $(\beta(\tau)=r . V(\tau)$; $\mathrm{r}$ is a constant coefficient). Another method to determine the HIV transmission rate is based on the viral load equilibrium. 


\section{Table 11(on next page)}

Table 11: Clinical and public health relevant problems of HIV dynamics.

Clinical and public health relevant problems of HIV dynamics that can be potentially addressed using multi-scale models. 
- How does the time-varying viral load and shedding rate since HIV infection impact the transmission rate between hosts?

- How does co-infection among HIV-infected individuals impact the HIV dynamics in the population?

- How does super-infection of multiple HIV strains among infected individuals impact the HIV dynamics in the population?

- How does within-host mutations of drug-sensitive and drug-resistant strains impact the HIV evolution in the population?

- How does timing of treatment initiation among infected individuals impact the HIV dynamics in the population?

- How does treatment compliance and interruption behavior of HIV-positive individuals impact HIV dynamics in the population?

- What is the impact of pre-exposure prophylaxis of high-risk HIV-negative individuals on HIV dynamics in the population?

- How can multi-scale HIV models be verified and validated with empirical data?

- How can the optimal layers from micro-biological (genomic, molecular, cellular, organ) to macro-social (individual, family, community, national, global) levels for multi-scale models of HIV dynamics be selected appropriately?

Table 11: Clinical and public health relevant problems of HIV dynamics. Clinical and public health relevant problems of HIV dynamics that can be potentially addressed using multi-scale models. 